Fungal Allergy and Pathogenicity 


\section{Chemical Immunology Vol. 81}

$\begin{array}{ll}\text { Series Editors } & \text { Luciano Adorini, Milan } \\ & \text { Ken-ichi Arai, Tokyo } \\ & \text { Claudia Berek, Berlin } \\ & \text { Anne-Marie Schmitt-Verhulst, Marseille }\end{array}$

KARGER $\quad \begin{aligned} & \text { Basel } \cdot \text { Freiburg } \cdot \text { Paris } \cdot \text { London } \cdot \text { New York } \cdot \\ & \text { New Delhi } \cdot \text { Bangkok } \cdot \text { Singapore } \cdot \text { Tokyo } \cdot \text { Sydney }\end{aligned}$ 


\title{
Fungal Allergy and Pathogenicity
}

\author{
Volume Editors Michael Breitenbach, Salzburg \\ Reto Crameri, Davos \\ Samuel B. Lehrer, New Orleans, La.
}

48 figures, 11 in color and 22 tables, 2002

KARGER $\quad \begin{aligned} & \text { Basel } \cdot \text { Freiburg } \cdot \text { Paris } \cdot \text { London } \cdot \text { New York } \cdot \\ & \text { New Delhi } \cdot \text { Bangkok } \cdot \text { Singapore } \cdot \text { Tokyo } \cdot \text { Sydney }\end{aligned}$ 


\section{Chemical Immunology}

Formerly published as 'Progress in Allergy' (Founded 1939)

Edited by Paul Kallos 1939-1988, Byron H. Waksman 1962-2002

\section{Michael Breitenbach}

Professor, Department of Genetics and General Biology, University of Salzburg, Salzburg

\section{Reto Crameri}

Professor, Swiss Institute of Allergy and Asthma Research (SIAF), Davos

\section{Samuel B. Lehrer}

Professor, Clinical Immunology and Allergy, Tulane University School of Medicine, New Orleans, LA

Bibliographic Indices. This publication is listed in bibliographic services, including Current Contents ${ }^{\circledR}$ and Index Medicus.

Drug Dosage. The authors and the publisher have exerted every effort to ensure that drug selection and dosage set forth in this text are in accord with current recommendations and practice at the time of publication. However, in view of ongoing research, changes in government regulations, and the constant flow of information relating to drug therapy and drug reactions, the reader is urged to check the package insert for each drug for any change in indications and dosage and for added warnings and precautions. This is particularly important when the recommended agent is a new and/or infrequently employed drug.

All rights reserved. No part of this publication may be translated into other languages, reproduced or utilized in any form or by any means electronic or mechanical, including photocopying, recording, microcopying, or by any information storage and retrieval system, without permission in writing from the publisher.

(C) Copyright 2002 by S. Karger AG, P.O. Box, CH-4009 Basel (Switzerland)

www.karger.com

Printed in Switzerland on acid-free paper by Reinhardt Druck, Basel

ISSN 1015-0145

ISBN 3-8055-7391-X 


\section{Contents}

\section{Foreword}

M. Breitenbach, Salzburg; R. Crameri, Davos; S.B. Lehrer, New Orleans, La.

\section{Introduction}

A.M. Chiu, J.N. Fink, Milwaukee, Wisc.

3 References

5 Impact of Current Genome Projects on the Study of Pathogenic and Allergenic Fungi

M. Breitenbach, Salzburg; R. Crameri, Davos; S.B. Lehrer, New Orleans, La.

6 Candida albicans Genome Project

7 Cryptococcus neoformans Genome Project

7 Aspergillus fumigatus Genome Project

8 The Postgenomic Era

8 References

10 Fungal Aerobiology: Exposure and Measurement

E. Levetin, W.E. Horner, Atlanta, Ga.

11 Sampling Equipment

13 Analysis

15 Patterns of Variation

19 Measurement Problems

22 Clinical Implications

24 Conclusions

25 References 


\section{Allergy to Basidiomycetes}

A. Helbling, K.A. Brander, Bern; W.E. Horner, Atlanta, Ga.;

S.B. Lehrer, New Orleans, La.

28 Prevalence of Airborne Basidiospores Including Indoor Exposure

30 Prevalence of Sensitization

31 Clinical Aspects

31 Respiratory Allergy

32 Bronchial and Nasal Challenges

32 Atopic Eczema

33 Contact Dermatitis

33 Food Allergy

33 Invasive Mycosis

34 Source Materials

35 Basidiomycetes as Allergens

35 B. edulis (cèpe)

35 Calvatia spp. (Puffballs)

36 Coprinus spp. (Inky Cap)

37 Ganoderma spp.

37 Pleurotus spp. (Oyster Mushroom)

38 Psilocybe spp.

39 Cross-Reactivity

40 Molecular Biological Approaches to Basidiomycete Allergens

40 Screening of C. comatus Phage Display Library - 7 Putative Allergens

41 Cop c 1, the First C. comatus Allergen

44 Cop c 2

44 Conclusions

44 References

48 The Allergens of Cladosporium herbarum and Alternaria alternata M. Breitenbach, B. Simon-Nobbe, Salzburg

49 Problems with Reproducibility of Mold Extracts and the Study of Mold Allergens

51 Experience with Specific Immunotherapy in the Treatment of Mold Allergies

54 Importance of Molecular Cloning Techniques

54 Cloning, Analysis, Production and Clinical Testing of the

Allergens of Cladosporium and Alternaria

54 Cloning Methods

57 The Major Allergen of A. alternata, Alt a1

59 The Major Allergen, Cla h1

59 Enolase, an Important Allergen in C. herbarum and A. alternata, Exhibits Cross-Reactive Properties

61 Epitope Mapping of C. herbarum Enolase

62 Other Allergens

63 A. alternata 
63 C. herbarum

66 Production of Highly Purified Alt a1 and A. alternata Enolase for Clinical Use

66 Alt a1

66 A. alternata Enolase

67 Clinical Study with Recombinant $A$. alternata Allergens

68 Discussion and Outlook

68 Acknowledgments

69 References

73 Molecular Cloning of Aspergillus fumigatus Allergens and Their Role in Allergic Bronchopulmonary Aspergillosis

R. Crameri, Davos

74 Host Defense Mechanisms and A. fumigatus-Related Diseases

75 A. fumigatus-Related Diseases

76 Diagnosis and Epidemiology of Allergic Bronchopulmonary Aspergillosis

77 Cloning and Molecular Characteristics of A. fumigatus Allergens

82 Clinical and Diagnostic Evaluation of Recombinant A. fumigatus Allergens

83 The Role of A. fumigatus Allergens in Allergic Bronchopulmonary Aspergillosis

86 Utilizing the Allergenic Repertoire of A. fumigatus Identified with Advanced Technologies

87 Conclusions

87 Acknowledgments

88 References

94 Defense Mechanisms of the Airways against Aspergillus fumigatus: Role in Invasive Aspergillosis

H.F. Kauffman, J.F.C. Tomee, Groningen

95 Overview of Manifestations of Aspergillosis

95 Nonpathogenic Saprophytic Colonization

96 Aspergilloma

96 Hypersensitivity-Induced Aspergillosis

96 Aspergillus Asthma

97 Allergic Bronchopulmonary Aspergillosis

98 Hypersensitivity Pneumonitis

99 Invasive Pulmonary Aspergillosis

99 Host defense against Aspergillus

99 Innate Defense Strategies of Airways against Fungi

105 The Adaptive Immunological Response

108 Effect of Immunosuppressing Agents on the Innate and Adaptive Defense Mechanisms

109 Concluding Remarks

110 References 


\section{Secreted Proteinases and Other Virulence Mechanisms of}

Candida albicans

M. Monod, Lausanne; M. Borg-von Zepelin, Göttingen

115 Site-Directed Mutagenesis and Genomics to Investigate Virulence Factors

116 Dimorphism

116 Switching System of C. albicans

118 Adherence

119 Secreted Hydrolases

119 Phospholipases

120 Secreted Aspartic Proteinases

121 Aspartic Proteinases in the Adherence Process

123 Aspartic Proteinases in Deep-Seated Candidiasis

124 Acknowledgment

124 References

129 Cutaneous Mycology

T. Hawranek, Salzburg

130 Pathogenesis of Cutaneous Fungal Infection

132 Clinical Mycology

132 Superficial Mycoses

132 Pityriasis versicolor

133 White Piedra

133 Black Piedra

134 Tinea nigra

134 Cutaneous Mycoses

134 Dermatophytosis (Ringworm, Tinea)

134 Special Clinical Patterns

134 Tinea corporis

138 Tinea inguinalis (Tinea cruris)

138 Tinea capitis

141 Tinea barbae

141 Tinea pedis ('Athlete's Foot')

142 Tinea manuum

142 Onychomycosis

143 Skin and Nail Infections by Molds

143 Scytalidium Species

144 Onychomycosis Caused by Scopulariopsis brevicaulis

144 Onychomycosis Caused by Other Molds

144 Tinea incognito

144 'Superficial' Candidiasis

145 Oral Candidiasis (Thrush)

146 Pseudomembranous Candidiasis 
Erythematous (Atrophic) Candidiasis

146 Candida Leukoplakia (Chronic Plaque-Like or Hyperplastic Candidiasis) Genital Candidiasis Candida Balanitis Vaginal Candidiasis

147 Congenital Candidiasis

148 Chronic Mucocutaneous Candidiasis

148 Other Forms of Candidiasis

149 Subcutaneous Mycoses

149 Sporotrichosis

149 Chromoblastomycosis

150 Mycetoma (Madura Foot)

150 Subcutaneous Zygomycosis

150 Entomophthoromycosis

150 Localized Mucormycosis

151 Lobomycosis

151 Rhinosporidiosis

151 Systemic (Deep) Mycoses Caused by Pathogenic Fungi

152 Coccidioidomycosis

152 Paracoccidioidomycosis

152 Histoplasmosis

153 Blastomycosis

153 Systemic (Deep) Mycoses Caused by Opportunistic Fungi

153 Candidiasis

154 Cryptococcosis

154 Systemic Zygomycosis

155 Aspergillosis

155 Pseudallescheriasis

155 Rare Mycoses

155 Hyphomycosis

156 Pheohyphomycosis

156 Hyalohyphomycosis

156 Protothecosis

156 Penicillium marneffei Infection

157 Laboratory Diagnosis

157 Collection of Material

157 Direct Examination (Potassium Hydroxide Test)

158 Culture and Additional Tests

159 Histopathology, Serology, Identification of Yeasts and Molds

163 Principles of Therapy

163 References 


\section{Toxins of Filamentous Fungi}

D. Bhatnagar, J. Yu, K.C. Ehrlich, New Orleans, La.

168 Mycotoxicosis

170 Mycotoxicology

170 Natural Occurrence of Mycotoxins

171 History of Mycotoxins

173 Classification of Mycotoxins

173 Economic Impact of Mycotoxins

176 Detection and Screening of Mycotoxins

176 Selected Mycotoxins

177 Aflatoxins

179 Toxic Polyketides Other Than Aflatoxins

179 Ochratoxins

181 Cyclopiazonic Acid

181 Patulin

182 Penicillic Acid

182 Citrinin

183 Sterigmatocystin

183 Zearalenone

184 Fumonisins

187 Trichothecenes

190 Alternaria Toxins

191 Neurotropic Mycotoxins

191 Ergot Alkaloids and Related Toxins

192 Other Neurotropic Mycotoxins

193 Management of Mycotoxin Contamination

193 Preharvest Control

194 Postharvest Control

196 Dietary Consideration

196 Summary

197 References

207 Phylogeny and Systematics of the Fungi with Special Reference to the Ascomycota and Basidiomycota

$H$. Prillinger, K. Lopandic, W. Schweigkofler, Wien; R. Deak, Budapest; H.J.M. Aarts, Wageningen-UR; R. Bauer, Tübingen, K. Sterflinger, G.F. Kraus, Wien, A. Maraz, Budapest

210 The Kingdom Mycobionta (Eumycota) or True Fungi

212 Morphological Differentiation within the Kingdom Mycobionta

215 Sexual Differentiation within the Kingdom Mycobionta

224 Phylogenetic Relationships among the Chytridiomycota and Zygomycota

226 Phylogenetic Relationships among the Ascomycota and Their Anamorphs

228 Hemiascomycetes

231 Protomycetes 
233 Euascomycetes

234 Chaetothyriales

235 Eurotiales

237 Onygenales

239 Hypocreales

242 Ophiostomatales

242 Phyllachorales

243 Sordariales

244 Microascales

244 Dothideales

246 Pleosporales

248 Leotiales

249 Pezizales

249 Phylogenetic Relationships of the Basidiomycota and Their Anamorphs

253 Urediniomycetes

255 Cystobasidiales

255 Microbotryales

256 Uredinales

257 Ustilaginomycetes

258 Malasseziales

258 Georgefischerales

259 Microstromatales

259 Ustilaginales

260 Hymenomycetes

261 Tremellales

263 Cantharellales

264 Gomphales

264 Thelephorales

265 Polyporales

267 Hymenochaetales

268 Russulales

268 Boletales

269 Schizophyllales

270 Agaricales

272 Genotypic Identification

275 Acknowledgments

275 References

294 Notes added in proof

296 Glossary

302 Author Index

303 Subject Index 


\section{Foreword}

Fungal organisms (yeasts and molds) are an increasing public health problem (Chiu and Fink) worldwide for several reasons. After transplantation surgery immunosuppressed patients frequently suffer from fungal infections which can become fatal; the AIDS pandemic, which is still on the increase, also leads to fungal infections that are difficult to treat and there is an increase in real and perceived allergic diseases which, in some developed countries, involve $20-30 \%$ of the population; a proportion of these allergies is due to inhaled fungal spores and other fungal material. Some of the older patients suffering from allergic or 'nonallergic' asthma are particularly prone to fungal infections of the lung. Moreover, fungal toxins (Bhatnagar et al.) still represent an important health problem both in humans and farm animals.

Exposure to fungal spores is ubiquitous and, therefore, of pivotal importance for the development of mycoses acquired via the respiratory tract. This situation has also led to increased public awareness of the importance of indoor air quality and to the emergence of aerobiology, which has established itself as a major environmental academic discipline (Levetin and Horner).

Fungal infections have led to an increasing demand for antifungal drugs. Compared to the well-known antibacterial antibiotics, these are generally less than satisfactory, because it is more difficult to combat eukaryotic than procaryotic pathogens, and severe side effects are still frequent. It is expected that fungal whole genome sequences (Breitenbach et al.), which are now being determined, will be very helpful in devising new antifungal drugs. Fungal genetics plays an increasing role in the study of clinically relevant fungi. Genome sequences will also lead the way to the discovery of new virulence factors which are important as drug targets. There are good reasons for hope, but at present no antifungal drug developed on the basis of fungal genomics is yet on the market.

Fungi are different from bacterial pathogens also because they are mostly opportunistic, that is they are present all the time in healthy individuals (for instance, on the skin), and only become dangerous in certain situations. A variety 
of pathological conditions, including impaired immune function, are believed to cause host susceptibility to fungal infections. The major reason for the increase in systemic mycoses is undoubtedly related to an increased number of patients with congenital or acquired immunodeficiency. Therefore, it is important to study not only the fungal pathogens but also the host factors that contribute to fungal infectivity (Kauffman and Tomee, and Monod and Borg-von Zepelin).

Until recently, the study of fungal allergy was still in its infancy. It is no exaggeration to say that modern cDNA cloning techniques caused a major breakthrough in this field. Before the advent of allergen cloning, it was difficult, for several reasons, to identify the relevant fungal allergens unequivocally. Commercially available fungal extracts were for the most part not satisfactory for a reliable diagnosis and were not authorized for specific immune therapy ('hyposensitization') in many countries. This situation will improve with the advent of well-defined pure recombinant fungal allergens (Helbling et al., Breitenbach and Simon-Nobbe, and Crameri).

Nearly all major systematic groups of fungi are now known to contain allergenic and/or pathogenic species (Prillinger et al.). Among the Ascomycota, the new sequence-based phylogeny defines three large groups: the Hemiascomycetes, the Protomycetes (Archiascomycetes) and the Euascomycetes. Presently there is some debate on whether the Protomycetes are primitive Ascomycota (Archiascomycetes) or a derived group of Ascomycota with similarities to the Basidiomycota (Prillinger et al.). Until recently, some Ascomycota (Aspergillus, Alternaria, Cladosporium, Penicillium, Candida and others) were called 'fungi imperfecti' (Deuteromycota), but are now recognized as close relatives of 'perfect' Ascomycota based on molecular systematics.

The Hemiascomycete, Candida albicans, is a very important pathogen and allergen, aspects of which are treated by Monod and Borg-von Zepelin. Among the Euascomycetes, Trichophyton rubrum causes superficial skin infections (Hawranek); Histoplasma capsulatum is an intracellular parasite of the monocyte/macrophage system occasionally causing fatal infections, and Aspergillus fumigatus is a very important allergen and pathogen that is able to colonize the human lungs. Some aspects of Aspergillus infections are the topic of the chapters by Crameri, and Kauffman and Tomee. Cladosporium herbarum and Alternaria alternata (Breitenbach and Simon-Nobbe) are Euascomycetes. They are important causes worldwide of allergies. Pneumocystis carinii, an important pathogenic member of the Protomycetes, is the most common cause of lung infection in AIDS patients.

Among the major groups of the Basidiomycota, only the Uredinomycetes contain practically no known pathogens and/or allergens. Rhodotorula mucilaginosa and Rhodotorula glutinis have occasionally been isolated from patients. Interestingly, Malassezia (previously called Pityrosporum) furfur, a human 
pathogen infecting the skin and hair follicles (Hawranek), is a member of the Ustilaginomycetes, a large group of plant pathogens. The most highly developed group of the Basidiomycota, the Hymenomycetes, contain a number of recently recognized important allergy-causing fungi: Coprinus cinereus, Psilocybe cubensis, and puffballs of the genus Calvatia, among others (Helbling et al.). Another Hymenomycete, Cryptococcus neoformans, is an important human pathogen causing the often fatal cryptococcosis of the lung and meningitis.

This volume clearly shows the importance of correct fungal systematics to understand the clinically relevant fungi. For this reason, we have included an extensive chapter on the new molecular fungal systematics. This chapter (Prillinger et al.) should be consulted whenever questions appear as to the correct systematic nomenclature and the older synonyms of a fungal organism. We are including a glossary because we feel that the highly specialized terminology, especially of clinical mycology and of systematic mycology, should be explained for nonspecialists.

This book addresses not only clinicians who want to learn more about clinically important fungi, but also allergologists, mycologists, biologists and lawyers concerned with the increasing number of lawsuits because of fungal spores in indoor air, which are claimed to be a major reason for 'sick building syndrome'.

We are very grateful to Thomas Nold and the members of the team of Karger (Basel, Switzerland) for their excellent cooperation and patience during the time of collecting and editing the chapters of this book. We are also very grateful to the authors of this book who have spent many days checking and rechecking every chapter, especially to Birgit Simon-Nobbe and to Hansjörg Prillinger. Finally, we thank our families for their support and confidence in the final success of this project.

M. Breitenbach, R. Crameri, S.B. Lehrer 